\title{
Tidal triggering of earthquakes in Longmen Shan region: the relation to the fold belt and basin structures
}

\author{
Qiang Li and Gui-Ming Xu \\ Research Center for Earthquake Prediction, Earthquake Administration of Jiangsu Province, Nanjing 210014, PR China
}

(Received December 30, 2010; Revised May 28, 2011; Accepted June 21, 2011; Online published September 18, 2012)

\begin{abstract}
We found a distinctive pattern of tidal triggering of earthquakes related to the fold belt and basin structures. We studied the correlation between tidal variations and seismic events in the Longmen Shan region. We divided this region into two subregions: one is located in the Songpan-Garze Fold Belt which has a soft and weakened crust; the other is located in the Sichuan Basin which has a relatively rigid and strong crust. The results of Schuster's test show that there is a higher correlation in the subregion of the Songpan-Garze Fold Belt than in the subregion of the Sichuan Basin. The reason for this distinctive triggering pattern is that the rock failure mechanism is related to the mechanical properties of the rocks: under conditions of high stress, different kinds of rocks have a different nonlinear behavior of rock deformation and fracture patterns. The nonlinear behavior of rock deformation, which is the prerequisite for a critical stress state in which the tidal stress could trigger an earthquake, increases as the rigidity and the strength of rocks decrease. Therefore, this triggering pattern is closely related to the properties of the crustal rocks of the Songpan-Garze Fold Belt and the Sichuan Basin.
\end{abstract}

Key words: Tidal triggering of earthquakes, Schuster's test, fold belt and basin structures.

\section{Introduction}

The problem of the tidal triggering of earthquakes has, for a long time, been of scientific interest (Stroup et al., 2007). Changes in tidal stress (Melchior, 1983; Wilcock, 2001) are significantly smaller compared with seismic stress drops (Kanamori and Anderson, 1975); however, in the majority of cases, their rates are much higher compared with the mean rates of changes in tectonic stress (Wilcock, 2001). Therefore, a small change in tidal stress has the possibility of triggering an earthquake when the stress reaches a critical state in the focal region.

An intriguing aspect of recent study is the location and timing pattern of the tidal trigger effects linked with the occurrence of some large seismic events. Research into the Tonga subduction zone has shown that high correlations were just seen in the few years previous to the 1982 South Tonga earthquake $\left(M_{\mathrm{w}} 7.5\right)$ near and in the coming fracture region of the great quake (Tanaka et al., 2002b). Research into the Sumatra region has also shown that clear correlations were detected as long as ten years prior to some large seismic events (Tanaka, 2006, 2010). Besides, some studies by Tanaka et al. (2006) show that this observational result is not widespread and may change in time and space within a certain area.

However, this aspect has been little studied, and we do not know what the space-time pattern of the tidal triggering effect is in fold belt and basin structures, such as the Longmen Shan region. In the present study, we investigate the

Copyright (c) The Society of Geomagnetism and Earth, Planetary and Space Sciences (SGEPSS); The Seismological Society of Japan; The Volcanological Society of Japan; The Geodetic Society of Japan; The Japanese Society for Planetary Sciences; TERRAPUB.

doi:10.5047/eps.2011.06.037 correlation between the earthquake events in the Longmen Shan region, China, and the tidal variations. We concentrate on the spatial and temporal pattern of this effect in relation to the Wenchuan $M 8.0$ earthquake and the structural setting of this region.

\section{Theoretical Tidal Stress}

The tide comprises two constituents (Tanaka et al., 2002a): one is the Earth tide affecting the solid strata, caused by the attraction of the Moon and the Sun, and the other is the ocean tide. Close to the ocean edges, the effect of ocean loading has to be taken into consideration due to the larger ocean tide effect when compared to Earth tides on solid strata at various times. Although the Longmen Shan region is slightly distant from the ocean edges, we have considered the effect of ocean loading for the sake of accuracy.

The Earth tide stress we use is calculated theoretically by using the Preliminary Reference Earth Model (Dziewonski and Anderson, 1981; Tsuruoka et al., 1995).

As to the stress components, some researchers use shear stress on the fault plane (Mohler, 1980; Heaton, 1982) and a stress tensor trace (Tsuruoka et al., 1995) as the tidal stress components. Others use tidal compressional stresses at the regional tectonic stress orientations (Tanaka et al., 2004), Coulomb stress amplitude (Cochran et al., 2004), and so on (Stroup et al., 2007; Métivier et al., 2009), as tidal stress components. For the Longmen Shan region, focal mechanisms are available for only a few earthquakes. To obtain dependable tidal triggering statistics, we require a certain number of seismic events. According to the study by Tanaka et al. (2004), earthquakes are inclined to occur when the regional tectonic stress is superposed by the tidal stress. Thus, we use the tidal compressional stress at the 
regional tectonic stress orientations (the azimuth of tectonic stress orientation of this region is $84^{\circ}$ according to the study by Xu et al. (1989)) as the tidal stress components for the purpose of obtaining a sufficient number of seismic events for a statistical test.

\section{Statistical Test}

The method to search for the tidal triggering of earthquakes is as follows (Tanaka et al., 2002b).

First, we allocate to each earthquake a phase angle of tidal stress based on the earthquake occurrence time. Using the maximum stress closest to the seismic occurrence time, we define the maximum as the tidal stress phase angle of $0^{\circ}$, and the preceding and following minimum as $-180^{\circ}$ and $180^{\circ}$, respectively. We linearly interpolate the time interval between these phases to define other phase angles.

Second, using the phase angle previously mentioned, we examine whether or not seismic events occur indiscriminately within the half daily tidal periodic variation by applying Schuster's test (Schuster, 1897; Heaton, 1982; Tsuruoka et al., 1995; Wilcock, 2001; Tanaka et al., 2002a). Schuster's test introduced a parameter $p$, whose value represents the probability of a random earthquake phase distribution. Therefore, a lesser $p$-value corresponds to a stronger correlation between tidal variations and earthquake occurrence. In this study, we use $p \leq 5 \%$ as the limit for significant correlation between tidal variations and seismic occurrence (Tanaka et al., 2002a; Stroup et al., 2007).

\section{Data}

We analyzed the correlation between tidal variations and earthquake occurrence in the Longmen Shan region of China, which is a seismically active region around the Longmen Shan fault belt. At 14:28 on May 12, 2008, Wenchuan County, located in the Longmen Shan region, was struck by a $M 8.0$ earthquake. The epicenter distribution of events occurring from 1978 to 14:28, May 12, 2008, in the Longmen Shan region (a total of 1788 earthquakes) is shown in Fig. 1(a) (data extracted from the earthquake catalogue of the China Earthquake Administration). The epicenter distribution of events (which are mostly the aftershocks) occurring from 14:29, May 12, 2008, to April 12, 2010 (a total of 1987 earthquakes) is shown in Fig. 1(b). Since clustering can confuse the analysis results (Young and Zurn, 1979), the clustered earthquakes were eliminated using the Reasenberg method (1985). The completeness magnitude estimated after performing a Gutenberg-Richter analysis is 2.4 .

\section{Results}

\subsection{The temporal pattern of the $p$-value in the Long- men Shan region}

In our research on the temporal pattern of the $p$-value in the Longmen Shan region, we followed analysis methods used in Tanaka's works (Tanaka et al., 2002b; Tanaka, 2006, 2010). By using the concept of a sliding window, we can calculate the temporal evolution of the $p$-value. Figure 2(a) details the variation with time of the $p$-value in the Longmen Shan region. A sliding window length of 1000 days and a step length of 100 days were used (a)

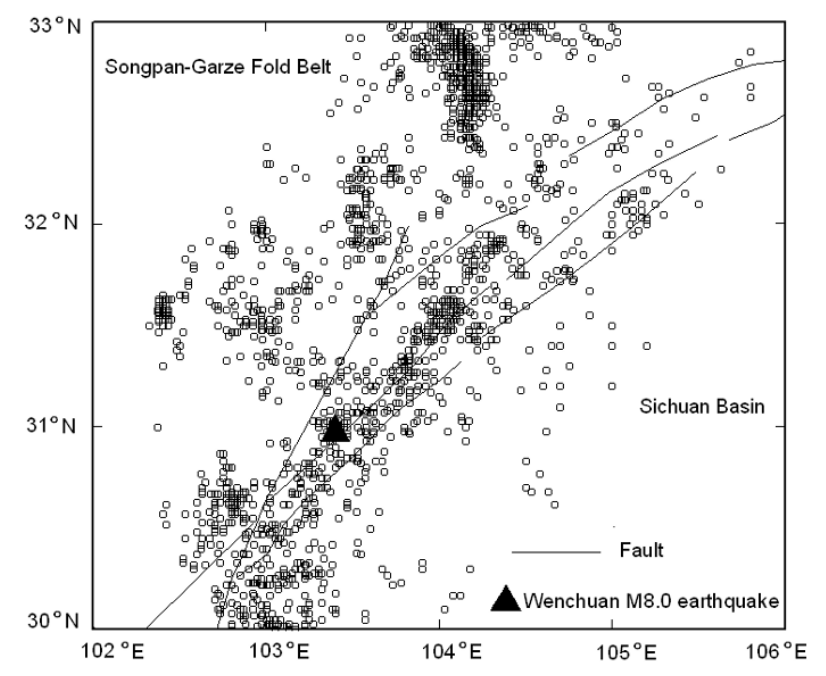

(b)

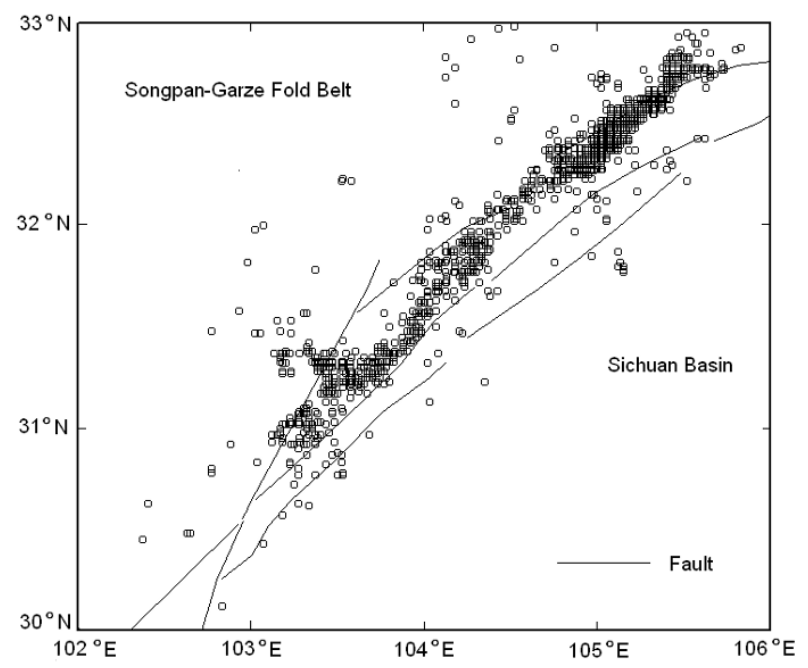

Fig. 1. (a) Epicenter distribution of events occurring from 1978 to 14:28, May 12, 2008, in the Longmen Shan region (a total of 1788 earthquakes). (b) Epicenter distribution of events occurring from 14:29, May 12, 2008, to April 12, 2010, in the Longmen Shan region (a total of 1987 earthquakes).

before the Wenchuan $M 8.0$ earthquake. After the main shock, a window length of 700 days was used. As can be seen from the figure, the $p$-value fluctuated more than $20 \%$ for the period of 11000 days to 2800 days before the Wenchuan $M 8.0$ earthquake. The $p$-value began to diminish 2700 days before the earthquake. The least value it achieved before this event was $2.2 \%$. After this earthquake, it abruptly increased, achieving a relatively high value of $31.1 \%$. This result indicates that there is an obvious distinction in phase angle choice between the preceding, and after, seismic event periods with respect to the Wenchuan $M 8.0$ event. Figure 2(b) details the phase angle frequency variations for the time period of 1800 days before the Wenchuan M 8.0 event. The data set includes 239 earthquakes occurring in this period. The result of Schuster's test shows a small $p$-value of $3.4 \%$. We note that the maximum phase angle frequency is close to $0^{\circ}$, at which the tidal compressional stresses at the regional tectonic stress orientations 
(a)

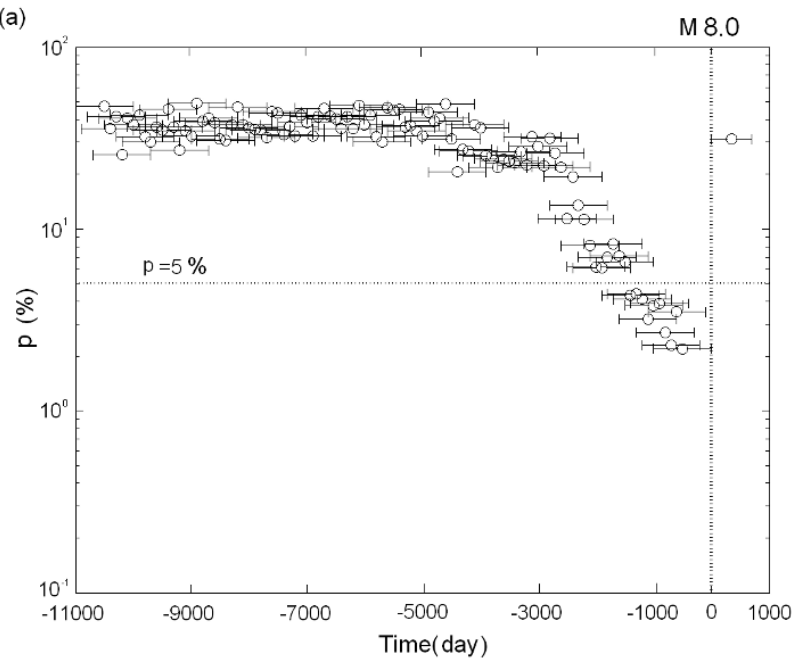

(b)

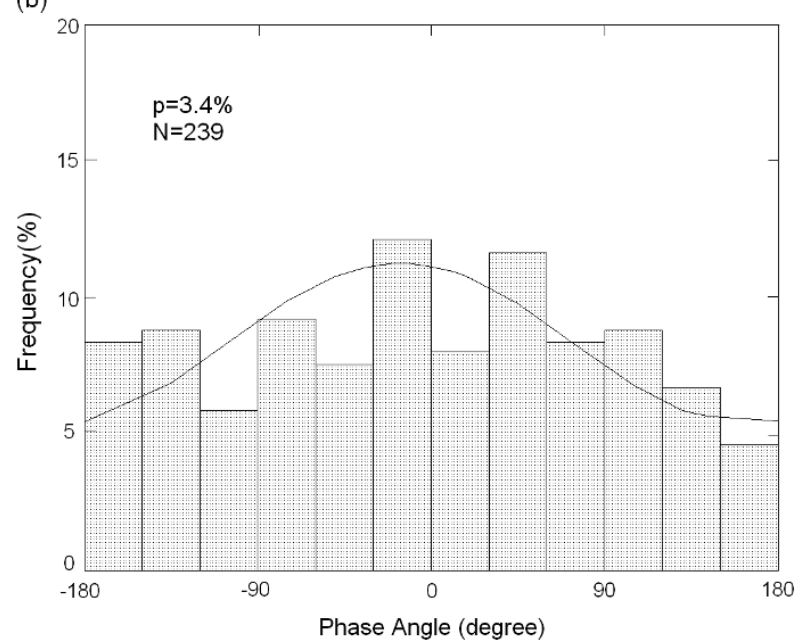

Fig. 2. (a) Change of $p$-value with time. The sliding window length of 1000 days, denoted by a horizontal line, is moved by 100 days before the Wenchuan $M 8.0$ earthquake. (b) Phase angle frequency variation for seismic events in the period 1800 days before the Wenchuan $M 8.0$ earthquake. The fine solid curve denotes a function of sinusoidal least squares fit to the variation.

are at their highest values, enhancing earthquake occurrence. This signifies that the observed small $p$-value before the Wenchuan $M 8.0$ earthquake can be attributed to the changes in the tidal compressional stresses at the regional tectonic stress orientations.

5.2 The time-space variations of $p$-value according to the geological features of Longmen Shan region

In order to obtain more valuable results, we have further investigated the time-space variations of the $p$-value according to the geological features of this region.

The Longmen Shan region, shown in Fig. 1, can be divided into two major tectonic units (Burchfiel et al., 1995; Liu et al., 2009): one is the Songpan-Garze Fold Belt, which has a soft and weakened crust (Liu et al., 2009); the other is the Sichuan Basin, which has a relatively rigid and strong crust (Liu et al., 2009). The Longmen Shan Fault Belt, which consists of three faults, forms the boundary between the Songpan-Garze Fold Belt and the Sichuan Basin on the surface of the ground (Chen and Wilson, 1996). The three faults extend together in the deep Earth crust and form

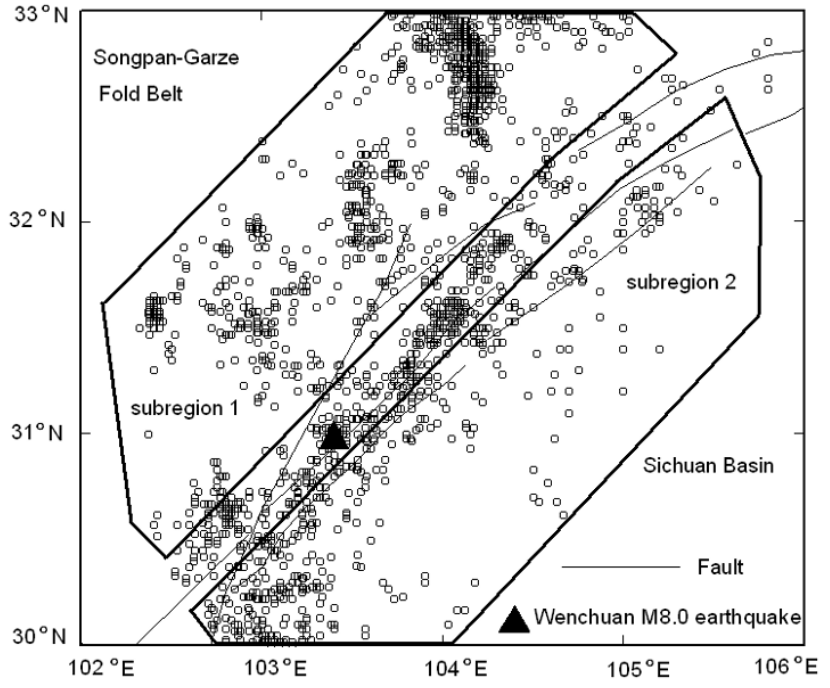

Fig. 3. Two subregions: Subregion 1 is located in the Songpan-Garze Fold Belt, while Subregion 2 is located in the Sichuan Basin.

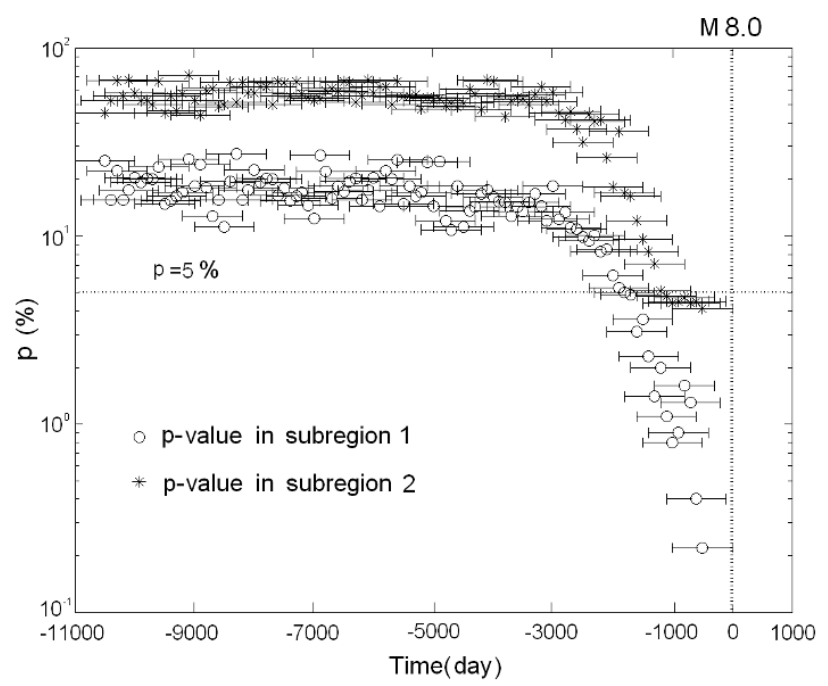

Fig. 4. Change of $p$-value with time in the two subregions for the period 11000 days preceding the Wenchuan $M 8.0$ event. The sliding window length of 1000 days, denoted by a horizontal line, is moved by 100 days. The small circles indicate the $p$-value in Subregion 1, while the asterisks indicate the $p$-value in Subregion 2.

the convergent boundary where the Songpan-Garze Fold Belt and the Sichuan Basin collide (Teng et al., 2009), and where the Wenchuan $M 8.0$ earthquake occurred. Taking this convergent boundary as a boundary line, we divide the above region into two subregions: Subregion 1 is mainly located in the Songpan-Garze Fold Belt, while Subregion 2 is mainly located in the Sichuan Basin. In order to eliminate the effect of the location of the boundary between these two subregions on the observed results, the location of the collision boundary is avoided (see Fig. 3).

Because the aftershocks of the Wenchuan M 8.0 earthquake are mostly located in the collision boundary (see Fig. 1(b)), we have focused on the variation of the $p$-value for the period before the main shock in the following studies of the two subregions. 
(a)

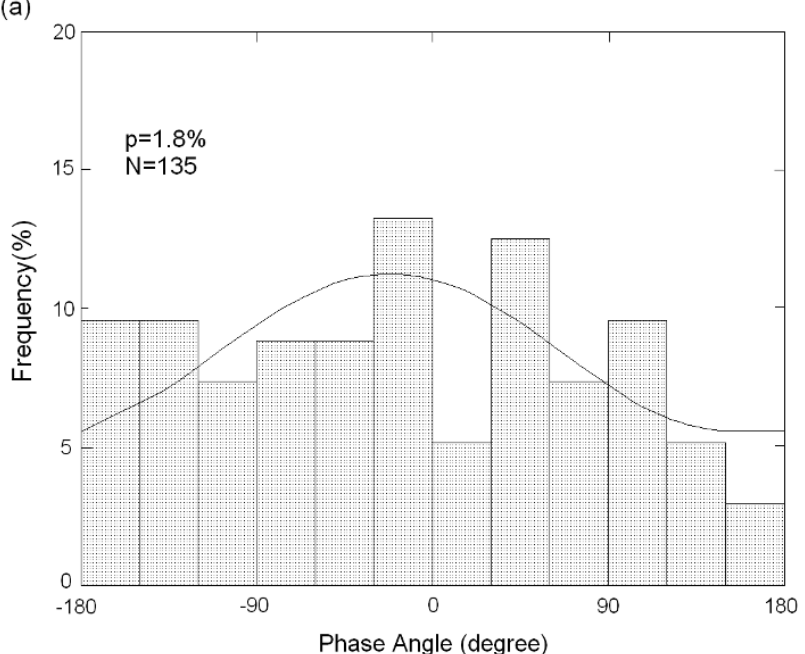

(b)

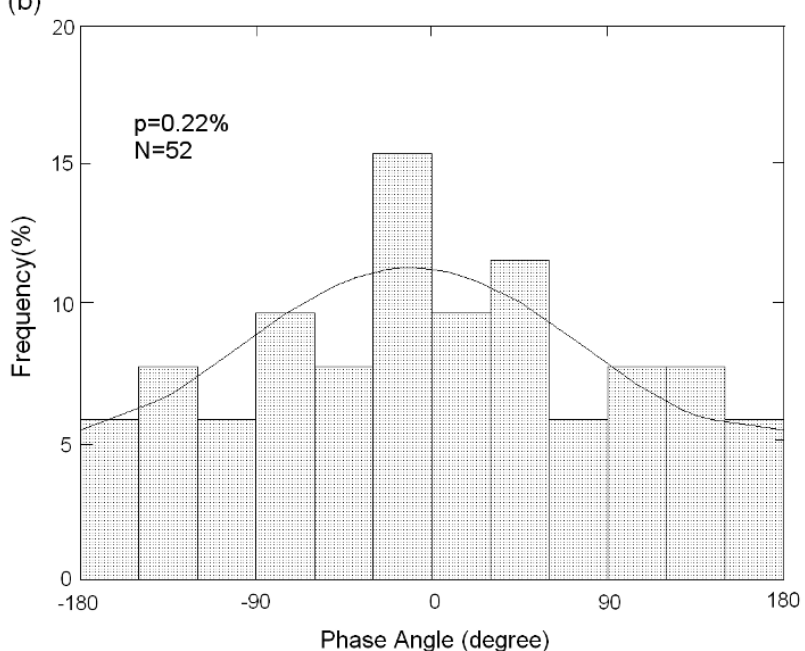

(c)

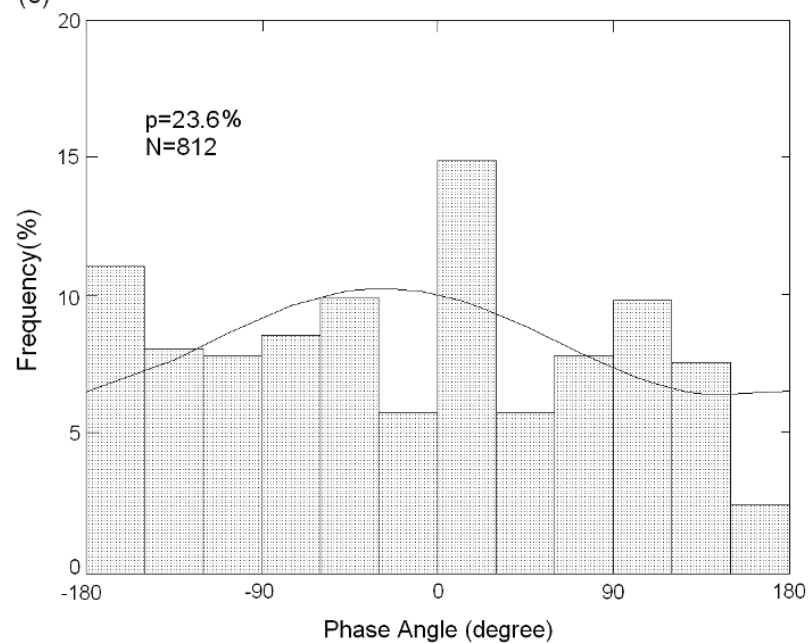

Fig. 5. (a) Phase angle frequency variation for seismic events in the period 2300 days before the Wenchuan $M 8.0$ earthquake in Subregion 1. The fine solid curve denotes a function of sinusoidal least squares fit to the variation. (b) Phase angle frequency variation for seismic events in the period 1000 days (i.e. the most strongly-triggered period) before the Wenchuan M 8.0 earthquake in Subregion 1. The fine solid curve denotes a function of sinusoidal least squares fit to the variation. (c) Phase angle frequency variation for seismic events in the period between 2300 to 11000 days before the Wenchuan $M 8.0$ earthquake in Subregion 1. The fine solid curve denotes a function of sinusoidal least squares fit to the variation.

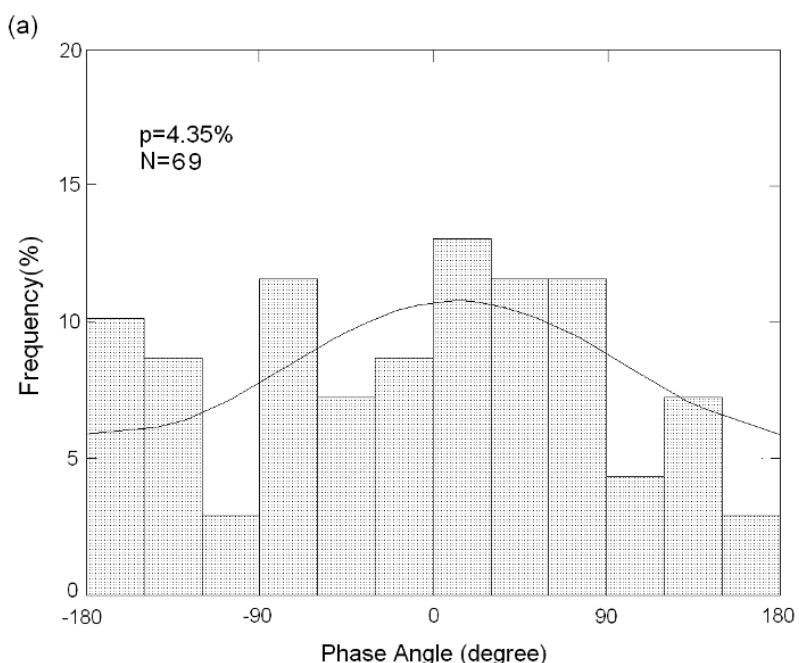

(b)

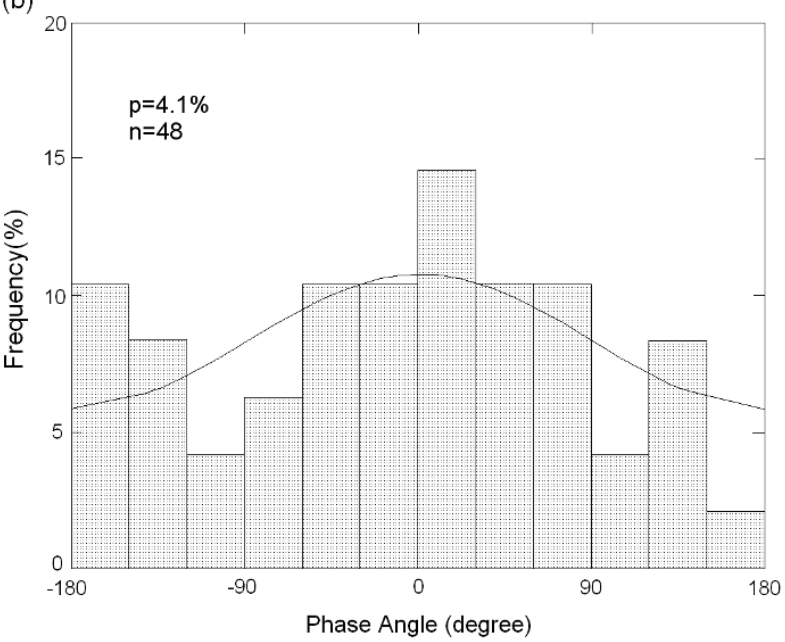

(c)

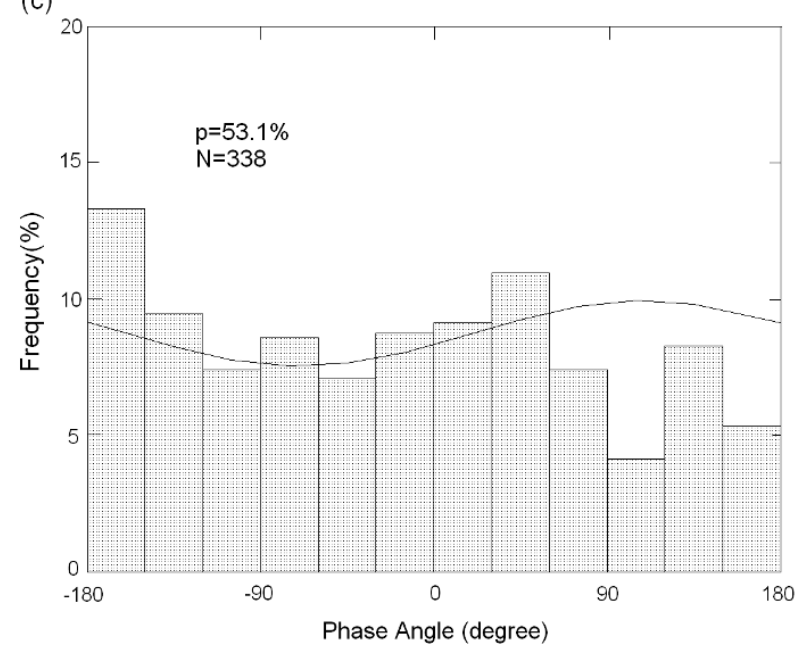

Fig. 6. (a) Phase angle frequency variation for seismic events in the period 1600 days before the Wenchuan $M 8.0$ earthquake in Subregion 2. The fine solid curve denotes a function of sinusoidal least squares fit to the variation. (b) Phase angle frequency variation for seismic events in the period 1000 days (i.e. the most strongly-triggered period) before the Wenchuan M 8.0 earthquake in Subregion 2. The fine solid curve denotes a function of sinusoidal least squares fit to the variation (c) Phase angle frequency variation for seismic events in the period between 1600 to 11000 days before the Wenchuan $M 8.0$ earthquake in Subregion 2. The fine solid curve denotes a function of sinusoidal least squares fit to the variation. 
Figure 4 shows the time-space variations of the $p$-value in these two subregions for the period 11000 days before the Wenchuan $M 8.0$ earthquake, where a time window of 1000 days is moved by 100 days. The time variations of the $p$-value in Subregions 1 and 2 are denoted by circles and asterisks, respectively. Comparing the $p$-value in Subregion 1 with that in Subregion 2, we find that the $p$-value in Subregion 1 , on the whole, is smaller than the $p$-value in Subregion 2: the average of the former is $14.7 \%$, while the average of the latter is $47.6 \%$. Further studies indicate that there are great differences in the $p$-values between Subregion 1 and Subregion 2. First, the low- $p(p \leq 5 \%)$ period in Subregion 1 is longer than in Subregion 2: the former is 2300 days, while the latter is 1600 days. Second, as can be seen in Figs. 5(a) and 6(a), the $p$-value for the low- $p$ period in Subregion 1 is much smaller than that in Subregion 2: the former is $1.8 \%$ while the latter is $4.35 \%$. Third, the smallest $p$-value in Subregion 1 is much smaller than that in Subregion 2: the former is $0.22 \%$, while the latter is $4.1 \%$ (see Figs. 5(b) and 6(b)). Lastly, as can be seen in Figs. 5(c) and 6(c), the $p$-value for the non-low$p(p>5 \%)$ period in Subregion 1 is much smaller than that in Subregion 2: the former is $23.6 \%$ while the latter is $53.1 \%$. From the above-mentioned differences, we deduce that there is a higher correlation between tidal variations and earthquake occurrences in Subregion 1 than in Subregion 2.

Obviously, the above phenomena are not random. They can be explained by the mechanism of the rock failure and the different mechanical properties of the crustal rocks of these two subregions.

\section{Discussion and Conclusions}

Our research on the correlation between tidal variations and earthquake occurrence in the Longmen Shan region has demonstrated that a high correlation appeared about 5 years before the Wenchuan $M 8.0$ earthquake. In the preseismic periods, a peak of the tidal phase angle distribution appeared near $0^{\circ}$, in which tidal compressional stresses at the regional tectonic stress orientations are at their highest values enhancing earthquake occurrence. This signifies that the observed small $p$-value before the Wenchuan $M 8.0$ earthquake can be attributed to changes of tidal compressional stresses at the regional tectonic stress orientations.

The results of a statistical analysis of the two subregions indicate that there is a higher correlation between tidal variations and earthquake occurrence in Subregion 1, located in the Songpan-Garze Fold Belt, than in Subregion 2, located in the Sichuan Basin. The reason for this distinctive pattern of tidal triggering of earthquakes is that the mechanism of rock failure is related to the mechanical properties of the rocks: under conditions of high stress, different kinds of rocks show a different non-linear behavior of rock deformation and fracture patterns because they have different stress-strain relationships (i.e. constitutive relations) (Lockner and Beeler, 2002; Ge et al., 2004); the non-linear behavior of rock deformation, which is the prerequisite for a critical stress state (Yin and Yin, 1991) in which the tidal stress could trigger an earthquake, increases as the rigidity and strength of rocks decrease (Jiao et al., 2003). Therefore, this triggering pattern is closely related to the properties of the crustal rocks of the Songpan-Garze Fold Belt and the Sichuan Basin.

Acknowledgments. We thank Professor S. S. Dong for helpful conversations. This work is supported by the United Fund of Earthquake Science of China (A08024).

\section{References}

Burchfiel, B., C. Zhiliang, L. Yupinc, and L. Royden, Tectonics of the Longmen Shan and adjacent regions, central China, Int. Geol. Rev., 37, 661-735, 1995.

Chen, S. F. and C. J. L. Wilson, Emplacement of the Longmen Shan Thrust-Nappe Belt along the eastern margin of the Tibetan Plateau, $J$. Struct. Geol., 18, 413-430, 1996.

Cochran, E. S., J. E. Vidale, and S. Tanaka, Earth tides can trigger shallow thrust fault earthquakes, Science, 306, 1164-1166, 2004.

Dziewonski, A. M. and D. L. Anderson, Preliminary reference Earth model, Phys. Earth Planet. Inter., 25, 297-356, 1981.

Ge, H. P., Y. Sun, W. B. Zhu, J. C. Guo, D. L. Liu, X. Y. Chen, F. Wang, and S. H. Wen, Experiment on the fracture behavior in rocks, Geol. J. China Univ., 10, 290-296, 2004 (in Chinese with English abstract).

Heaton, T. H., Tidal triggering of earthquakes, Bull. Seismol. Soc. Am., 72, 2181-2200, 1982.

Jiao, M. R., C. A. Tang, G. M. Zhang, Y. L. Shi, and W. K. Hou, Numerical test of influence of mesoscopic heterogeneity on macroscopic behavior of rock failure and seismic sequence types, Chinese J. Geophys., 46, 659-666, 2003 (in Chinese with English abstract).

Kanamori, H. and D. L. Anderson, Theoretical basis of some empirical relations in seismology, Bull. Seismol. Soc. Am., 65, 1073-1095, 1975.

Liu, Q. Y., Y. Li, J. H. Chen, B. Guo, S. C. Li, J. Wang, X. Q. Zhang, and S. H. Qi, Wenchuan M8.0 earthquake preliminary study of the S-wave velocity structure of the crust and upper mantle, Chinese J. Geophys., 52, 309-319, 2009 (in Chinese with English abstract).

Lockner, D. A. and N. M. Beeler, Rock failure and earthquakes, Int. Geophys. Ser., 81, 505-538, 2002.

Melchior, P., The Tides of the Planet Earth, Pergamon, New York, 1983.

Métivier, L., O. D. Viron, C. P. Conrad, S. Renault, M. Diament, and G. Patau, Evidence of earthquake triggering by the solid earth tides, Earth Planet. Sci. Lett., 278, 370-375, 2009.

Mohler, A. S., Earthquake/earth tide correlation and other features of the Susanville, California, earthquake sequence of June-July 1976, Bull. Seismol. Soc. Am., 70, 1583-1593, 1980.

Reasenberg, P., Second-order moment of central California seismicity, 1969-1982, J. Geophys. Res., 90, 5479-5495, 1985.

Schuster, A., On lunar and solar periodicities of earthquakes, Proc. R. Soc. Lond., 455-465, 1897.

Stroup, D. F., D. R. Bohnenstiehl, M. Tolstoy, F. Waldhauser, and R. T. Weekly, Pulse of the seafloor: Tidal triggering of microearthquakes at 9 500N East Pacific Rise, Geophys. Res. Lett., 34, L15301, 2007.

Tanaka, S., Tidal triggering of earthquakes precursory to the $2004 \mathrm{Mw}=$ 9.0 off Sumatra Earthquake, in 4th Int. Workshop on Statistical Seismology, 9-13, Graduate University for Advanced Studies, Kanagawa, Japan, 2006.

Tanaka, S., Tidal triggering of earthquakes precursory to the recent Sumatra megathrust earthquakes of 26 December 2004 (Mw 9.0), 28 March 2005 (Mw 8.6), and 12 September 2007 (Mw 8.5), Geophys. Res. Lett., 37, L02301, 2010.

Tanaka, S., M. Ohtake, and H. Sato, Evidence for tidal triggering of earthquakes as revealed from statistical analysis of global data, J. Geophys. Res., 107, 2211, 2002a.

Tanaka, S., M. Ohtake, and H. Sato, Spatio-temporal variation of the tidal triggering effect on earthquake occurrence associated with the 1982 South Tonga earthquake of Mw 7.5, Geophys. Res. Lett., 29, 1756, doi:10.1029/2002GL015386, 2002 b.

Tanaka, S., M. Ohtake, and H. Sato, Tidal triggering of earthquakes in Japan related to the regional tectonic stress, Earth Planets Space, 56, 511-516, 2004.

Tanaka, S., H. Sato, S. Matsumura, and M. Ohtake, Tidal triggering of earthquakes in the subducting Philippine Sea plate beneath the locked zone of the plate interface in the Tokai region, Japan, Tectonophysics, 417, 69-80, 2006.

Teng, J. W., C. Liu, L. G. Han, X. M. Ruan, Y. F. Yan, and Y. Q. Zhang, The dynamical mechanism for medium rupture and motion of deep matter for Wenchuan-Yingxiu Ms 8.0 Earthquake, 2008, J. Jilin Univ. (Earth 
Sci. Ed.), 39, 559-583, 2009 (in Chinese with English abstract).

Tsuruoka, H., M. Ohtake, and H. Sato, Statistical test of the tidal triggering of earthquakes: contribution of the ocean tide loading effect, Geophys. J. Int., 122, 183-194, 1995.

Wilcock, W. S. D., Tidal triggering of microearthquakes on the Juan de Fuca Ridge, Geophys. Res. Lett., 28, 3999-4002, 2001.

Xu, Z. H., S. Y. Wang, Y. R. Huang, and A. J. Gao, The tectonic stress field of Chinese continent deduced from a great number of earthquakes, Chinese J. Geophys., 32, 636-647, 1989 (in Chinese with English abstract).
Yin, X. C. and C. Yin, The precursor of instability for nonlinear systems and its application to earthquake prediction, Sci. China, 34, 977-986, 1991.

Young, D. and W. Zurn, Tidal triggering of earthquakes in the Swabian Jura, J. Geophys., 45, 171-182, 1979.

Q. Li (e-mail: lqdzjybzx@126.com) and G.-M. Xu 